\title{
Derecho de preferencia de los accionistas
}

Manuel de la Puente y Lavalle

El arrículo 115 de la ley general de Sociedades, llamada en adelante «la Ley", establece en su segundo párrafo que las limitaciones a la libre transmisibilidad de la acción son válidas para la sociedad cuando están expresamente impuestas por el estatuto y sólo en el caso de las acciones nominativas, agregando en el tercer párrafo que en ningún caso las limitaciones pueden significar la prohibición de transmitir las acciones.

Puede observarse que se requiere para la validez de las limitaciones frente a la sociedad que ellas estén expresamente impuestas por el estatuto, siendo redundante la referencia a que sólo afecten a las acciones nominativas, desde que las acciones al portador fueron suprimidas por el decreto supremo 287-68-HC.

Llama la atención que siendo la sociedad anónima una sociedad de capitales, en la cual no juega un rol significativo la calidad personal de los accionistas, y que estando representadas sus acciones por títulos valores cuya característica esencial es la circulación, se permita imponer limitaciones a la libre transmisibilidad de las acciones. Conviene conocer las razones que han llevado a gran parte de las legislaciones, como la nuestra, a aceptar estas limitaciones.

BROSETA ${ }^{1}$, pese a reconocer que la transmisibilidad de las acciones es un principio esencial del derecho de sociedades anónimas, respondiendo la división del capital social en acciones a un doble motivo: recoger capital del ahorro privado y conceder el incentivo de la transmisibilidad de la cualidad de socios a los inversores - por lo cual se afirma que la transmisibilidad de la acción ha sido el mecanismo que ha permitido ocupar a la sociedad anónima un lugar preeminente en la economía

Broseta Pons, Manuel, Restricciones estatutarias a la libre transmisibilidad de acciones, Editorial Tecnos S.A., Madrid, 1984, p. 26. 
capitalista moderna-, admite que en la realidad no siempre la sociedad anónima responde a estos principios.

«Por el contrario - dice-, es muy frecuente, sobre todo en España, donde abundan las sociedades de pequeño y medio capital, y las sociedades familiares en forma de anónimas, que la consideración personal de los socios sea mayor de lo que corresponde a la estructura ideal de la sociedad anónima -destinada a regir la gran empresa capitalista-como colector de grandes masas de capitales, cualquiera que sea su procedencia. Por razones de muy diversa naturaleza y para obtener distintos fines, es muy frecuente que en el momento constitutivo se reúnan "determinadas" personas que quieren defender la integridad personal del grupo, basada en una comunidad de conocimientos técnicos; de creencias ideológicas; de intereses; en la pertenencia a una misma familia; en el interés de que un "grupo" no pierda la mayoría y el control sobre la sociedad, para lo cual es necesario impedir que las acciones neutrales sean adquiridas y acrezcan las del grupo minoritario rival; en el deseo de mantener el control sobre una sociedad filial; en mantener un equilibrio de fuerzas entre dos grupos de una misma sociedad, para impedir la entrada de competidores en calidad de accionistas que puedan perturbar la marcha de la sociedad; o para obstaculizar el ingreso de extranjeros en la sociedad que pongan en peligro los intereses nacionales en determinadas industrias. Y precisamente para defender estos intereses y conservar la integridad personal ante la entrada de accionistas extraños, o para mantener el equilibrio de fuerzas en el seno de la sociedad, se suelen utilizar diversos procedimientos, que establecen un control sobre las transmisiones de las acciones y, por tanto, sobre la sustitución de unos accionistas por otros."

Puede observarse que las limitaciones a la libre transmisibilidad de las acciones de las sociedades anónimas obedecen prácticamente en todos los casos a un propósito de desviar el rol para el cual fue ideada la sociedad anónima, hacia la satisfacción de intereses personales que no condicen con la esencia capitalista y abierta de estas sociedades. Es por ello que las limitaciones a la libre transmisibilidad de las acciones de una sociedad anónima deben tratarse con carácter restrictivo, por constituir regímenes de excepción.

Existen tres clases de limitaciones a la libre disponibilidad de las acciones que no llegan a significar la prohibición de transmitir las mismas, que son: 1 . las legales, cuando están contenidas en la ley; 2 las convencio- 
nales, cuando son los propios accionistas quienes las convienen como un acto parasocial, y 3. las estatutarias, cuando son todos los accionistas quienes las acuerdan en el momento constitutivo, o todos o la mayoría de ellos, mediante acuerdo de junta general, previa reforma estatutaria.

Aparte de las limitaciones legales, que son obligatorias por mandato de una norma legal, el artículo 115 de la Ley sólo reconoce la validez, para la sociedad, de las limitaciones impuestas por el estatuto, que pueden ser de dos clases: 1. las cláusulas de consentimiento, que subordinan la validez de las transferencias a la previa aprobación de la sociedad, y 2. las llamadas cláusulas de conocimiento, opción o tanteo-que denominaremos, para evitar confusión con otras figuras similares, cláusulas estatutarias de preferencia-, según las cuales se confiere a la sociedad, o a otros titulares, el derecho de adquirir con preferencia, dentro de determinado plazo $y$ por un precio fijado a priori o señalable en virtud de bases preestablecidas, las acciones que se pretende enajenar ${ }^{2}$.

Con relación a estas últimas, surge la duda respecto a si la cláusula estatutaria sobre el derecho de adquirir las acciones con preferencia debe identificarse con el pacto de preferencia a que se refiere el inciso 2 del artículo 1582 del Código Civil, según el cual es nulo el pacto de preferencia en virtud del cual se impone al comprador la obligación de ofrecer el bien al vendedor por el tanto que otro proponga, cuando pretenda enajenarlo.

Para disipar esta duda conviene referirse a la doctrina que comenta la antigua ley de Sociedades Anónimas española de 1951, cuyo artículo 46 ha sido el antecedente inmediato del artículo 115 de la ley general de Sociedades peruana.

$\mathrm{Al}$ respecto, $\mathrm{URIA}^{3}$ y $\mathrm{BERGAMO}^{4}$ opinan que la cláusula estatutaria de preferencia, pese a denominársele también tanteo, si bien no puede identificarse con el derecho preferencial de tanteo que regulan las leyes civiles, guarda innegable parentesco con él. Señala BERGAMO, como diferencias entre ambas instituciones, que mientras en el tanteo común son los propios contratantes quienes fijan libremente el precio, en la cláusula estatutaria de preferencia el valor suele fijarse con arreglo a métodos más o menos objetivos o automáticos; y que así como el retracto supone una transferencia inicial válida, que va seguida de otra a favor del retrayente,

\footnotetext{
2 Garrugues, Joaquín, y Uria, Rodrigo, Comentario a la ley de Sociedades Anónimas, Imprenta Aguirre, Madrid, 1976, tomo I, p. 528.

3 Ibidem, tomo I, p. 530.

4 Bergamo, Alejandro, Sociedades Anónimas (Las acciones), Prensa Castellana S.A., Madrid, 1970, tomo I, p. 644 .
} 
el acto dispositivo formalizado en contra de la cláusula de tanteo se reputa nulo frente a la sociedad, porque su ejercicio supone un contrato único, que considera no consumada la transmisión subrepticia.

RUBiO ${ }^{5}$, por su parte, considera que las cláusulas estatutarias de preferencia ("preémption", en la terminología francesa) responden a un sistema complejo de tanteo y retracto, según el cual la sociedad señala un comprador de las acciones o se reserva la facultad de adquirirlas ella misma.

Para la debida comprensión de estas opiniones debe tenerse presente que en Derecho español el tanteo es «la facultad que por ley o costumbre jurídica tiene una persona para adquirir algo con preferencia a los compradores y por el mismo precio", mientras que el retracto-convencional o legal- es "el derecho que tiene el titular del mismo, de adquirir una cosa por igual precio, dejando sin efecto una transmisión anterior». En el tanteo, el que quiere enajenar una cosa no puede hacerlo sin ofrecerla previamente en iguales condiciones a quien tiene el derecho de tantear; $y$ en el retracto el retractante se sustituye en el lugar del adquirente una vez que la operación con el tercero ha sido efectuada ${ }^{6}$. CASTÁN ${ }^{7}$ señala esta diferencia en el sentido de que el tanteo es «el derecho de preferencia que una persona tiene para la adquisición de una cosa, en el caso que el dueño quiera enajenarla", y el retracto es "el derecho de preferencia que uno tiene para la adquisición de una cosa cuando el dueño la ha enajenado, subrogándose en el lugar del comprador mediante abono al mismo del precio que entregó y gastos de contrato que se le pudieran ocasionar".

Resulta así que la cláusula estatutaria de preferencia es en Derecho español semejante al tanteo, el cual, a su vez, es un derecho de preferencia para adquirir, por el tanto, el bien que una persona desea enajenar. La distinción entre la cláusula estatutaria de preferencia y el derecho de tanteo radica en que aquélla concede un derecho convencional mientras que éste es de carácter legal.

Conviene aclarar que las cláusulas estatutarias de preferencia tienen siempre un origen convencional, pues dependen de la voluntad de los fundadores, si es que figuran en el acto fundacional, o de la voluntad de todos o la mayoría de los socios, si se introducen en una reforma estatutaria posterior.

\footnotetext{
Rubio, Jesús, Curso de Derecho de sociedades anónimas, Editorial de Derecho Financiero, Madrid, 1974, p. 149.

- Enciclopedia Juridica OMEBA, Bibliográfica Omeba, Buenos Aires, 1968, tomo XXV, p. 1032.

Cita de la cita.
} 
La indicada distinción entre el derecho de carácter legal y el de carácter convencional determina, en cambio, una aproximación de la cláusula estatutaria de preferencia al pacto de preferencia de que trata el inciso 2 del artículo 1582 del Código Civil peruano, desde que éste, por ser precisamente un pacto, tiene también naturaleza convencional.

Sin embargo, esta aproximación, si bien muy grande, no llega a ser una identificación absoluta, por cuanto la cláusula estatutaria de preferencia establece una preferencia en favor de la sociedad o de otros titulares, mientras que el pacto de preferencia impone al comprador la obligación de ofrecer el bien al vendedor.

Cabe preguntarse si esta diferencia es determinante y, para ello, conviene conocer la razón por la cual el codificador peruano optó por declarar la nulidad del pacto de preferencia en favor del vendedor. De acuerdo con la Exposición de Motivos del contrato de compraventa ${ }^{8}$, el pacto de preferencia tiene inconvenientes menores que el pacto de mejor comprador, pues sólo puede imputársele que dificulta el tráfico patrimonial, dado que no puede aceptarse directamente una oferta de compra sino que es necesario mantenerla vigente e informar sobre su existencia al vendedor para que manifieste si hace uso o no de su derecho de preferencia. "Sin embargo -se agrega-, este menor inconveniente es todavía suficiente para hacer aconsejable que deje de regularse en el Código el pacto de preferencia. Aun limitado el ejercicio del derecho a un plazo corto, como es el de treinta días que señala el artículo 1435 del Código Civil de 1936, la fluidez de la contratación sufre con esta traba que desalienta a los posibles adquirentes del bien de formular ofertas que, en el fondo, están supeditadas a la voluntad del vendedor. Las codificaciones modernas han dejado de legislar sobre el pacto de preferencia, tal como puede observarse en los Códigos de Italia, de Corea, del Líbano, de Grecia, de Quebec (Canadá), de Portugal, de Bolivia, etc.»

Puede observarse que la razón determinante de la nulidad establecida por el inciso 2 del articulo 1582 del Código Civil es el desaliento de los posibles adquirentes del bien de formular ofertas que, en el fondo, están supeditadas a la voluntad del vendedor, lo que afecta la fluidez de la contratación. El mismo desaliento se produce cuando las ofertas de adquisición pueden quedar sin efecto por voluntad de la sociedad o de otros titulares.

\footnotetext{
* Código Civil. Exposición de Motivos y comentarios, Delia Revoredo de Debakey (compiladora), Okura Editores S.A., Lima, 1985, tomo VI, p. 203.
} 
Por otro lado, el pacto de preferencia, a semejanza de la cláusula estatutaria de preferencia, obedece al propósito de evitar que los bienes materia de la compraventa pasen a manos de extraños al vendedor, o, al menos, de personas ingratas a éste.

Finalmente, comentando el artículo 1368 del Código Civil argentino, según el cual "pacto de preferencia" es la estipulación de poder el vendedor recuperar la cosa vendida, entregada al comprador, prefiriéndolo a cualquier otro por el tanto, en caso de querer el comprador venderla, afirma LOPEZ DE ZAVALIA9 que, si bien el citado artículo habla de una prelación en favor del vendedor, es evidente que puede constituirse una prelación (ius protimiseos) en favor de quien no sea el vendedor. Nada impediría, agrega, que se constituyera en favor de quien no tuviera otra relación con el obligado que la que emergiera del pacto de prelación.

Desaparece así toda diferencia entre la cláusula estatutaria de preferencia y el pacto de preferencia.

En estas condiciones, por aplicación del aforismo latino "Ubi eadem ratio, idem jus" ("a igual razón, igual derecho"), debe considerarse que, tratándose de la compraventa de acciones, la cláusula estatutaria de preferencia, por constituir un pacto de preferencia, queda comprendida en la nulidad prevista por el inciso 2 del artículo 1582 del Código Civil.

Podría objetarse que se está aplicando a la cláusula estatutaria de preferencia, que opera únicamente en el campo del Derecho societario, una nulidad propia del contrato civil de compraventa, pero debe tenerse presente que de conformidad con el artículo IX del Título Preliminar del Código Civil, las disposiciones de este código se aplican supletoriamente a las relaciones y situaciones jurídicas reguladas por otras leyes, siempre que no sean incompatibles con su naturaleza. Esta incompatibilidad no se produce en el presente caso, por cuanto no sólo según el articulo 2112 del mismo código los contratos de compraventa mercantil, como podría ser la compraventa de acciones con la finalidad de revenderlas, con ánimo de lucrar en la ganancia, se rigen por las disposiciones del Código Civil, sino también y muy especialmente porque las limitaciones a la libre transmisibilidad de las acciones de una sociedad anónima no responden a la naturaleza de esta sociedad.

Obsérvese que se limita la nulidad de la cláusula estatutaria de preferencia a la compraventa de acciones, por cuanto sólo es nulo el derecho de preferencia pactado en el contrato de compraventa. Esta nulidad no

Lopez de Zavalía, Fernando J., Teoría de los contratos, Víctor P. de Zavalía Editor, Buenos Aires, 1976, Parte especial, tomo I, p. 239. 
alcanza a las cláusulas de limitación de transmisibilidad de acciones por medio de contratos distintos a la compraventa.

Cabría pensar que tratándose del contrato de compraventa el pacto de preferencia se estipula dentro del marco del mismo contrato, mientras que en el caso de la cláusula estatutaria de preferencia ella se encuentra en el estatuto social, que es algo extraño al contrato de compraventa. Sin embargo, no debe olvidarse que la cláusula estatutaria de preferencia se aplica cuando el accionista se propone celebrar un contrato de compraventa de sus acciones, de tal manera que sólo se actualiza por razón de la proyectada celebración de este contrato. Si bien la cláusula estatutaria de preferencia no es un pacto del contrato de compraventa, se convierte en tal cuando llega la oportunidad de formularse la oferta del contrato de compraventa, desde que la oferta lleva necesariamente incorporada, como integrante de la misma, la cláusula estatutaria de preferencia.

Si bien es verdad que el artículo 115 de la Ley permite las cláusulas estatutarias de preferencia, no es menos cierto que el numeral 2 del artículo 1582 del Código Civil es una norma imperativa dictada con posterioridad a la ley general de Sociedades, desde que sanciona con nulidad el pacto de preferencia, por lo cual, en la medida que exista incompatibilidad entre la norma dispositiva contenida en el artículo 115 de la Ley y la norma imperativa contenida en el numeral 2 del artículo 1582 del Código Civil, prima la segunda.

No podría decirse que la Ley es una norma de carácter especial y que el Código Civil es una de carácter general, por lo cual no existe incompatibilidad, y que la norma antigua (la Ley) continúa rigiendo al lado de la norma nueva (el Código Civil) ${ }^{10}$, desde que el numeral 2 del artículo 1582 del Código Civil es una norma especial (el pacto de preferencia) contenida en una norma general (el Código Civil) que es incompatible con otra norma especial (validez de las limitaciones a la libre transmisibilidad de la acción) contenida en una norma general (la Ley). Existe, por lo tanto, incompatibilidad entre el numeral 2 del artículo 1582 del Código Civil y el artículo 115 de la Ley.

Recuérdese que, de conformidad con el artículo I del Título Preliminar del Código Civil, la derogación de una ley se produce por declaración expresa, por incompatibilidad entre la nueva ley y la anterior o cuando la materia de ésta es íntegramente regulada por aquélla.

\footnotetext{
11) Coviello, Nicolás, Doctrina general de Derecho civil, Unión Tipográfica Editorial Hispano-Americana, México, 1938, p. 105.
} 
Cabe, por lo tanto, llegar a la conclusión de que es nula la cláusula estatutaria de preferencia que figura en el estatuto de una sociedad anónima, en el caso de compraventa de las acciones de dicha sociedad.

No es el propósito del presente ensayo proscribir las cláusulas estatutarias de preferencia, cuya utilización es cada vez más frecuente en la práctica societaria, sino destacar el peligro constituido por la existencia de no despreciables razones que justificarían la invocación de su nulidad, por lo cual es conveniente dictar las normas legales pertinentes para conjurar este peligro. 